\section{EFFECTIVE, EFFICIENT BACKFILLING}

Quality Endodontic Distributors Ltd are the UK distributors of the Obtura Max heated gutta percha system, the proven answer to enhance endodontic success.

Supported by emphatic clinical history, the Obtura Max heated gutta percha system rapidly fills and obturates even the most difficult root canals more completely, in less time, and with less patient discomfort than any other method.

Used by key opinion leaders worldwide, the Obtura system has been an integral part of the armamentarium of successful endodontists for over 20 years. It delivers controlled and predictable results, ensuring the most effective and efficient 'backfilling' technique possible. With a choice of different size needles, condensable thermosoftened gutta percha can be used to 'backfill' any root canal system without leaving voids.

The sleek modern design of the Obtura Max unit includes five preset programmes, soft touch controls and easy clean surfaces. The lightweight, ergonomically designed handpiece helps reduce operator fatigue.

Reader response number 60

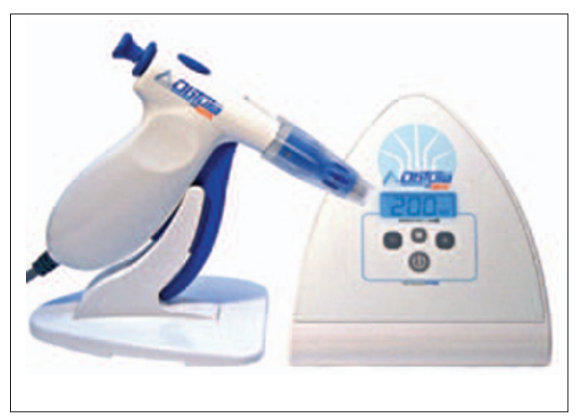

\section{PERFECT CORDLESS} OBTURATION

QED's Superendo B\&t-beta and alpha II cordless obturation devices form the perfect combination.

The Superendo B\&L-beta enables fast and easy delivery of warm obturation material for the endodontic backfill technique, facilitating rapid obturation of even the most difficult root canals more completely, in less time, and with less patient discomfort. Cordless, compact and easy to handle, it features variable temperature settings which allow practitioners to control the flow characteristics of the material; a rechargeable lithium ion battery which supports hours of use from a single charge; and a choice of $23 \mathrm{~g}$ and $25 \mathrm{~g}$ needle sizes with $360^{\circ}$ swivel for improved access.

Supplied with three tips, the Superendo BEtL-alpha II is the ultimate in cordless warm vertical compaction devices and supersedes old-fashioned cable machines.

It features multiple temperature settings $\left(150^{\circ} \mathrm{C}, 180^{\circ} \mathrm{C}, 200^{\circ} \mathrm{C}\right.$ and $230^{\circ} \mathrm{C}$ ) to accommodate both gutta percha and resilon, with a quick heating tip that reaches temperature within ten seconds. Completely cordless, compact, lightweight and ergonomically designed it incorporates a rechargeable lithium-ion battery which facilitates multiple uses on a single charge and allows the operator to complete many cases without the need to recharge. It comes complete with a tip, so is immediately ready to use, with a full range of optional tips available separately.

Reader response number 63

The CEREC system enables dentists to create all-ceramic restorations in-house. The CEREC SW 4.0 system guides the user step by step through the entire production procedure. The software functions and options adapt themselves dynamically as the work proceeds. Only those items that are relevant are displayed at any given time on the uncluttered user interface.

The software upgrade is available free of charge to CEREC Club members. Reader response number 62

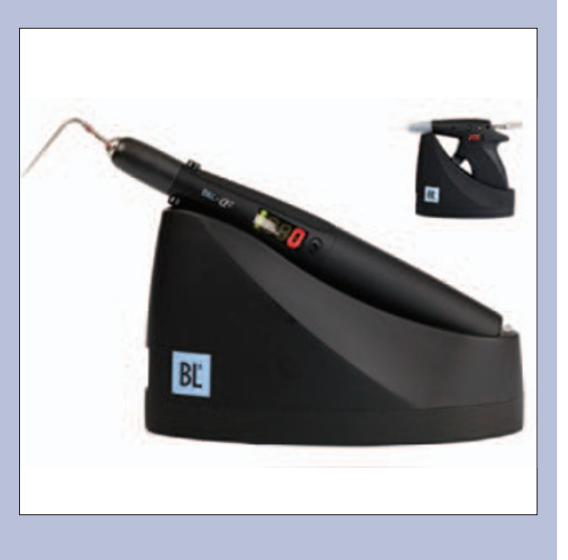

